\title{
Numerical analysis of passive strategies for energy retrofit of existing buildings in Mediterranean climate: thermal mass and natural ventilation combination
}

\author{
Filippo Calcerano ${ }^{1, *}$, Carlotta Cecchini ${ }^{2}$, and Letizia Martinelli ${ }^{2}$ \\ ${ }^{1}$ National Research Council of Italy - CNR, Institute for Technologies Applied to Cultural Heritage ITABC, Via Salaria km. \\ 29.300, 00016 Monterotondo, Italy \\ ${ }^{2}$ Department of Planning, Design and Technology of Architecture, Sapienza University of Rome, Via Flaminia 72,00196 Rome, \\ Italy
}

Received: 4 January 2017 / Accepted: 13 March 2017

\begin{abstract}
The study investigates the potential of coupling natural ventilation and thermal storage systems to improve hygrothermal comfort and reduce energy consumption during summer season in an existing building in the Mediterranean. It aims at bridging the knowledge gap between designers, researchers and building scientists, fostering a multidisciplinary approach and promoting numerical simulation of the energy performance of buildings within architectural professional practice. The study analyses the interaction between six natural ventilation systems (single sided ventilation through facade openings; cross ventilation through facade openings, inlet wind tower, thermal chimney, evaporative cool tower, earth pipes) and with two thermal storage typology (heavy and medium-light) within four strategic Italian location (Rome, Naples, Messina and Catania). For each interaction we perform a numerical dynamic simulation of indoor comfort, indoor air quality and energy consumption during the summer period, on a reference building model corresponding to the most common Italian typology. Results show that the use of the chosen systems ensures significant reductions of discomfort hours and energy consumption in all configurations. The study also highlights the high efficiency of non invasive systems (single-sided and cross ventilation with automatic control present discomfort hours reduction and energy consumption reduction above $68 \%$ for all combinations) and the significant influence of the daily thermal range value on the performance of systems without air pre-treatment.
\end{abstract}

Keywords: building performance simulation / building energy simulation / EnergyPlus ${ }^{T M} /$ energy refurbishment / existing building stock / Mediterranean climate / cooling

\section{Introduction}

The global consumption of primary energy in Europe depends for over $40 \%$ on buildings' demand: the existing building stock uses approximately $40 \%$ of economy's incoming materials and is responsible for over $45 \%$ of the total amount of greenhouse gases produced [1].

An increasing concern about rational use of energy and the limits of land urbanization identifies the great potential of energy refurbishment of existing buildings [2,3] for energy consumption reduction and environmental impact mitigation. Energy refurbishment consists in applying the most appropriate technology to achieve improved energy performance while maintaining satisfactory levels

\footnotetext{
* e-mail: filippo.calcerano@itabc.cnr.it
}

of service and indoor hygrothermal comfort, under operational constraints [4]. For this reason, within Directive 2010/31/EU, that upgrades Directive 2002/91/EC on Energy Performance of Buildings, European Union recognizes energy refurbishment as one of the main strategies to achieve European Energy target of 20\% energy demand reduction for 2020 compared to $1990[5,6]$.

Within Mediterranean area, traditional historical architecture has flourished following a significant harmonization with the reference climate, corresponding to relatively high energy performances [7]. However, since the industrial revolution and its confidence in the limitless availability of low-cost energy, environmentally conscious design weakened, while the overall use of HVAC systems replaced traditional know-how based on passive thermal and hygrometric control [8]. This circumstance determined a separation of competencies between the architect, 
responsible for the shape of the building, and the engineer, dealing with the operation systems. Despite the vast environmental impact and economic cost of this separation, the idea of neutralizing the effects of site and climate only trough engineering, regardless of architecture, is still deeply rooted in the construction practice [9].

Conversely, an integrated approach on building design, based on passive or hybrid strategies, proves able to capitalize on the interdependent behaviour of the building and its environment, in line with Mediterranean tradition.

Given the strong relationship between climate and energy performance of buildings, research on passive strategies has progressed differently in Europe according to the specific climatic conditions. Northern Europe has promoted an established practice in passive heating, while Mediterranean countries have encouraged so far the analysis and implementation of passive cooling strategies against summer overheating; due to the complexity of the phenomena involved, studies are still progressing [10]. On account of this discrepancy, the European Directive 2002/ 91/EC [11] has established clear rules for energy saving for the winter season and little more than quality provisions for feasible strategies for the summer season [12].

This academic and regulatory asymmetry between Northern and Southern Europe requirements mistakenly assimilates a "high performance building" to a building that minimise infiltration and heat loss during winter, causing a number of side effects in Southern Europe buildings during summer, such as [13,14]:

- the reduction of buildings' thermal storage elements, as an indirect effect of envelope insulation promotion within Europe;

- the standardization of materials and technologies, in contrast with Mediterranean traditional passive cooling strategies, based on site-specific approaches of thermal storage, air permeability and natural ventilation;

- the numerous power outages caused by excessive summer energy consumption and the increase of summer peak demand of electricity, produced by the deployment of artificial cooling. This issue imposes an additional stress on national energy nets, forcing the construction of new power plants to meet rising peaks [15].

Mechanical ventilation is also responsible for the largest increase in energy consumption of the building sector in recent years $[16,17]$. On the other hand, natural ventilation, coupled with thermal storage, exhibits a high potential for reducing energy consumption for Mediterranean climate, where thermal energy demand and passive energy supply diverge [18]. In fact, natural ventilation facilitates heat dispersion of daily thermal loads by promoting convection heat exchange between the internal surface of thermal storage elements and air, so that naturally ventilated buildings consume roughly half the energy of artificially conditioned buildings and can sustain adequate thermal conditions all year round [19-21]. Moreover, numerous studies show that occupants of naturally ventilated buildings feel more comfortable compared to occupants of mechanically ventilated buildings, also because air velocity fluctuations, arising from natural ventilation, have a more pleasant effect on humans than uniform fields of mechanical ventilation air flow [19-22].
In order to implement natural ventilation and thermal storage in energy refurbishment, it is essential to analyse in advance the complex relationship between these passive strategies and environmental, technological, architectural and site-specific factors [23]. A proper energy numerical simulation constitutes therefore a crucial starting point for optimized interventions [24], as long as it considers the building as a system of interrelated elements that can be globally optimised, rather than the sum of a number of elements designed and optimised separately for subsystems $[25,26]$. In fact, the impact of strategic decisions on energy and environmental performance of a building is more significant the more these decisions are close to the early stages of the intervention process [27]. Besides, interventions involving more areas in a given point of the spaceenvironment are more effective in controlling the indoor environment than an approach differentiated in times and stages, in terms of efficiency and sustainability [28].

Numerical simulation conveys the behaviour representation for a given building in a specific stage of its development through a simplified model, whose purpose is to provide information on the building potential performance and energy consumption. The model reduces the physical entities of the real world and the phenomena related to them to a certain level of abstraction, depending on the simulation purposes [25].

The resolution of the model generally progresses with the development of the design phases, allowing to compare step by step the energy performance of several design alternatives, rather than accurately predicting the energy performance of a single design solution in absolute terms [26]. The numerical simulation takes into account the socalled "sensitive variables", i.e. the energy trends that affect the most the final result of the simulations, hence the objectives to be achieved through them [29].

The current paper addresses the effect of natural ventilation, coupled with thermal storage through numerical simulation, applied to an apartment model representing the most widespread existing Italian typology. The aim of the study is to verify the significance of natural ventilation and thermal storage on the energy behaviour of buildings and especially their effect on summer comfort and energy consumption reduction in Mediterranean climate. The analysis takes into account four cities in Italy, within the Mediterranean climate, with three different thermal ranges: Rome, Naples, Messina and Catania.

\section{Strategies description}

\subsection{Thermal storage}

Thermal storage is a passive optimisation and rationalisation strategy, particularly effective when energy demand and supply are divergent. It shows a high potential to capitalize on solar radiation, the most influencing factor of building energy balance, and on the recovery of thermal energy that would otherwise be lost [30]. Several types of thermal storage can be distinguished [31], e.g.

- sensible heat storage, due to the thermal capacitance of building materials; 
- latent heat storage, based on the material phase change from solid to liquid state and vice-versa, in relation to a melting threshold, depending on the material itself;

- chemical storage, a long-term chemical process that triggers within the material itself.

Buildings usually implement mostly the sensible heat storage, since every material always absorbs and retains heat, depending on its own thermo-physical properties and the temperature differential. The storage principle can be indirect when the gain is indirect and the thermal mass is directly exposed to the air of the interior space and direct when thermal mass is exposed to the heat source (i.e. a sunexposed massive envelope). Both principles have traditionally been the prominent thermal storage strategy of Mediterranean archetypes. During summer, daily solar gains are mainly absorbed by the thermal masses of building elements and later released outside during the cooler hours of the day, depending on the thermal wave shift of the elements employed. During winter, daily solar gains are released in the interior space during the late afternoon-evening, when most required, partially satisfying heating demand [23]. In every season the internal thermal mass acts as a thermal flywheel and in case of overheating, heat dissipation strategies, i.e. natural ventilation and superficial convective motions, become essential to achieve indoor hygrothermal comfort.

In order to be considered for thermal storage, construction materials must possess a proper thermal diffusivity, which controls the depth reached by the diurnal thermal wave inside each architectural component: materials with a high thermal diffusivity are more effective to store heat deeper than those with a low diffusivity value [32].

A proper design of thermal storage elements is theoretically able to keep the temperature of the interior space close to $22^{\circ} \mathrm{C}$ [33] by absorbing/releasing heat by convection between the element surface exposed to the interior space and the space itself and by radiation between the element, the surrounding surfaces and the outdoor environment [27].

Directly irradiated elements are most effective for thermal storage, while elements that are indirectly irradiated and exposed to the indoor environment are more proper for indoor temperature management during summer [34]. However, construction elements performance for thermal storage depends on several environmental, architectural and technological variables affecting the thermal behaviour of the building, e.g. climate, walls orientation, building operation and usage, mutual position of insulation and thermal storage and occupants' behaviour.

Thermal storage is most effective when interacting with intermittent heat sources or in conditions of fluctuating temperature, as the amplitude of temperature oscillation is a prerequisite to the thermal storage performance, especially during summer, when the dissipation of excessive thermal gains is paramount [35-37]. In climates with a daily temperature variations greater than $15^{\circ} \mathrm{C}$ and where the average outside temperature is close to the range of thermal comfort (about $20-25^{\circ} \mathrm{C}$ ), high thermal storage buildings are more likely to maintain summer indoor hygrothermal comfort without HVAC systems, as long as the outside temperatures do not exceed $36^{\circ} \mathrm{C}$. Thermal storage elements performance is considered yet acceptable when the diurnal temperature variation exceeds $10^{\circ} \mathrm{C}$, because it is still generally possible to maintain the temperature oscillation of the internal air temperature within $2-3{ }^{\circ} \mathrm{C}$.

The distribution change of thermal storage elements depending on orientation is mainly impractical for energy refurbishment, which applies to existing buildings. However, a preliminary analysis of their position enhances the feasibility and efficiency of the intervention, enabling more effective usage and operation patterns. Facades facing north are generally exposed to very low solar radiation, mainly diffused, thus requiring rather thermal insulation implementation than thermal storage. Facades facing east are characterized by a medium irradiation, concentrated in the middle of the morning, demanding a direct thermal storage or a very long shift (i.e. greater than $14 \mathrm{~h}$ ), able to store heat until the early evening $[27,38]$; this latter intervention can be unfeasible for energy refurbishment both in economic and practical terms. West-oriented facades requires at least six hours of time lag, because their time of maximum heat gain is very close to the sunset. The south-exposed facades require a longer time lag because the maximum heat gain occurs around 13:00, very far from the sunset. The same occurs for elements continuously exposed to solar radiation (i.e. plan roofs): in this case, the amount of irradiation is such as to require very high thermal mass, which implies serious technical difficulties due to the increasing of structural loads.

\subsection{Natural ventilation systems}

Ventilation permits the periodical exchange of air between a confined interior space and the exterior, regulating the concentration of air pollutants and affecting the hygrothermal conditions of the space [39]. Buildings must be ventilated in order ensure adequate levels of indoor air quality (IAQ) through air changes throughout the entire year. Natural ventilation (NV) is the type of ventilation driven only by natural means, either wind or buoyancy (for temperature difference or height of the envelope openings difference within the building or between the building and outdoor space) [40-42]. In Mediterranean climate, it is possible to comply with hygrothermal comfort and IAQ requirements during spring, summer and autumn only with natural ventilation, maximizing heat dissipation, while in winter the exchanged air constitutes an heat loss to be limited by passive means (pretreatment). Heat exchanges in ventilation occur through the heat transfer fluid of air by convection between air and building surfaces using other natural or artificial elements (like the same air, the ground, the water, the sky or the building mass) as thermal flywheel.

The main natural ventilation systems (NVS) are [38]: - Cross ventilation (CV). This natural ventilation system is wind-driven through opposite envelope openings. It has a medium-high flow rate, depending on the wind incidence angle, the ratio between the height and depth of the room and the presence of obstacles to the flow. 
- Single-sided ventilation (SSV). This natural ventilation system is mainly wind-driven through envelope openings on the same side of the building. The NVS is less efficient in terms of flow rate compared to CV and is more influenced by the temperature difference between outside and inside and by the height difference between the openings.

- Downward ventilation (DV). This natural ventilation system is mainly wind-driven and uses ad inlets windcatcher on wind tower at higher heights than the envelope. Capturing the wind at greater heights than the space to be ventilated allows achieving higher flow rates.

- Upward ventilation (UV). This natural ventilation system is buoyancy-driven and generally uses envelope openings placed at different heights or wind towers. The flow rate depends on the temperature difference between outside and inside, the height differences between the openings and the duct section.

Ventilation techniques (VT) classify natural ventilation according to the mean to obtain hygrothermal comfort:

- Body ventilation (BV) is mainly used for cooling purpose, it is based on convective exchanges between air and the occupants' body and it depends on air speed and the temperature difference between air and skin [38].

- Structural ventilation (SV) is mainly used for cooling purposes, it is based on convective exchanges between external air and the mass of the building and it depends on daily thermal range, thermal inertia of the structures, flow speed and direction [43]. The absence of occupants often allows for greater air flow and lower temperature during the night.

- Room ventilation (RV) is used both for cooling and heating purposes and it is a mix of body and structural ventilation as it is based on convective exchanges between air, the mass of the buildings and the occupants in the internal environment. The maximum flow/rate is thus limited by the presence of occupants, imposing to avoid discomfort from excessive air speed inside the building.

Another important feature of natural ventilation is the heat exchange type (HET) that defines the natural medium used for the thermal exchanges [38]:

- microclimatic heat exchange uses external air as natural medium;

- evaporative heat exchange uses water as natural medium through latent heat;

- geothermal heat exchange uses the ground as natural medium, through buried earth pipes in which the air flow trades heat with the ground thermal mass;

- radiative heat exchange generally uses night sky as natural medium. Air flows on a high-emittance surface that, at night and in conditions of clear sky and low humidity, transfers heat to the night sky cooling the air that circulates then inside the building.

The technological systems currently available to capitalise NVS in an energy refurbishment project can be classified as Physical (PE) and Non-Physical (NPE) elements [43], as shown in Table 1.

\section{Methods}

\subsection{Reference climate and city selection}

This study follows Pinna climatic classification, which specifies Köppen-Geiger classification for Italian climatic zones (Fig. 1), focusing on the Mediterranean climatic areas of Italy [48].

We take into account the following subtypes of Pinna classification:

- subtropical (Csa prone to Bs): humid tropical climate with very hot summer, prone to arid climate, with average temperature above $18^{\circ} \mathrm{C}$, low and irregular rainfall;

- mild temperate (Csa): humid tropical climate with very hot and dry summer, with average temperature of the hottest month above $22^{\circ} \mathrm{C}$;

- sub-coastal (Csb prone to $\mathrm{Cfb}$ ): humid temperate climate, with hot summer and average temperature of the hottest month below $22^{\circ} \mathrm{C}$.

Several studies show that, under certain climatic conditions (fulfilled by Italian Mediterranean climate), an acceptable daily thermal range (TR) of air temperature of about $15^{\circ} \mathrm{C}$ is able to maintain the temperature of a confined environment within the limits of comfort [49]. The thermal range amplitude represents therefore a prerequisite for the optimal operation of both thermal storage and natural ventilation systems, especially under summer conditions, when the dissipation of daily heat load is required $[33,35]$. As the study is based on summer conditions, we propose a further characterization of the reference climate, based on three different average temperature ranges:

- optimum temperature range: above $13^{\circ} \mathrm{C}$;

- acceptable temperature range: between $10^{\circ} \mathrm{C}$ and $12^{\circ} \mathrm{C}$;

- low temperature range: less than $9^{\circ} \mathrm{C}$.

Thus, we take into account the differences in daily thermal range choosing among the three Mediterranean climate subtypes four strategic locations: Rome, Naples, Catania and Messina (Tab. 2). The choice of Catania and Messina enables the comparison between optimum and low thermal range on the effect of natural ventilation systems and thermal storage for the warmer summer conditions of subtropical climate. Input data for the simulation derive from the Climatic data of the four cities Climate design data 2009 ASHRAE Report, based on the IGDG of the corresponding weather station for each city.

\subsection{Reference simulation building model}

In Europe, residential buildings constitute approximately $75 \%$ of the building stock and are very high energy consumers, as they were mainly built before any law on energy saving and energy efficiency in the building sector was promulgated [2]. In Italy, the majority of residential buildings were built between 1961 and 1981 [50-52] and they exhibit the highest energy consumption of the building stock, as shown in Figure 2.

Typically, these buildings have the following main features: 
Table 1. Physical and non-physical elements in natural ventilation.

\begin{tabular}{lllc}
\hline \multicolumn{3}{c}{ Physical elements } \\
\hline NVS & VT & HET & Description \\
\hline
\end{tabular}

Openings on the building envelope

CV, SSV, DV, UV BV, SV, RV Microclimatic

Ventilated facade and roof

CV, SSV, DV, UV BV, SV, RV Microclimatic and radiative

They represent a context-based necessary feature for NV optimisation and they are widely used, especially in hot and middle season. Openings trigger and define the path of air flow inside the building, being at the same time an effective source of natural light. Wing walls may be used in combination with openings to increase the pressure difference between two windows and therefore the induced natural ventilation [44]

Used all year around, they are composed by wall two layers separated by an air gap with openings to the outside and/or inside, allowing the air flow to and from the air gap. During summer, buoyancy air circulation subtracts heat from the building by convection. During winter, the gap may be closed, to exploit the insulating effect of static air, or opened, to dissipate the vapour in the gap, thus avoiding condensation. Passive systems, i.e. Trombe-Michel wall, can allow specific outside-inside circulation

Courtyards, bioclimatic atria, sunspaces and buffer spaces VP, CV, UV SV, RV Microclimatic

Used all year around, these systems act as thermal mediators. Courtyards are more efficient on low rise buildings, while bioclimatic atria are more efficient over a certain building height [45]. Buffer spaces and sunspaces are both thermal and ventilative intermediate environments between the inside and the outside. During winter, they can be used as thermal store for pre-heated supply air, whilst in summer they can be used as air extractors [39].

Wind towers

DV, UV

BV, SV, RV Geothermal, evaporative, radiative Used all year around, wind towers are morphological-constructive elements with a vertical development that allows either upward or downward NV. They are usually associated with other ventilation systems, generally at the bottom (such as underground earth pipes or openings on the building), or at the top of the tower (i.e. windcatchers), or in synergy with particular heat exchange strategies, i.e. evaporative system or vegetation.

Buried earth pipes

DV, UV BV, SV, RV Geothermal

They are used all year. During the passage in the ducts, air temperature come to be close to ground temperature, which is warmer than the outside temperature in winter and cooler in summer thanks to its thermal stability during the year. This system can be independently used in summer and in winter as air thermal pre-treatment for other heating systems. 
Table 1. (continued).

\begin{tabular}{|c|c|c|c|}
\hline \multicolumn{4}{|c|}{ Non physical elements } \\
\hline NVS & $\mathrm{VT}$ & HET & Description \\
\hline \multicolumn{4}{|l|}{ Manual control } \\
\hline $\mathrm{CV}, \mathrm{SSV}, \mathrm{DV}, \mathrm{UV}$ & $\mathrm{BV}, \mathrm{SV}, \mathrm{RV}$ & Microclimatic & $\begin{array}{l}\text { Manual control, generally applied to the openings } \\
\text { on the building envelope, allows users to adjust } \\
\text { the indoor conditions for thermal comfort and air } \\
\text { quality according to their subjective perception. If } \\
\text { a user can have the direct control on the } \\
\text { environment is generally willing to accept a wider } \\
\text { range of comfort conditions [46]. }\end{array}$ \\
\hline \multicolumn{4}{|l|}{ Automatic control } \\
\hline DV, UV & $\mathrm{BV}, \mathrm{SV}, \mathrm{RV}$ & Microclimatic & $\begin{array}{l}\text { Automatic control requires the installation of } \\
\text { sensors capable of measuring the necessary } \\
\text { parameters required for the application of } \\
\text { control strategies from actuators [47]. Even if } \\
\text { automatic control is usually more effective than } \\
\text { manual control in terms of energy consumption } \\
\text { reduction [40,46], the design of these systems } \\
\text { must take into great consideration users' needs } \\
\text { without forcing any occupants behaviour. }\end{array}$ \\
\hline
\end{tabular}

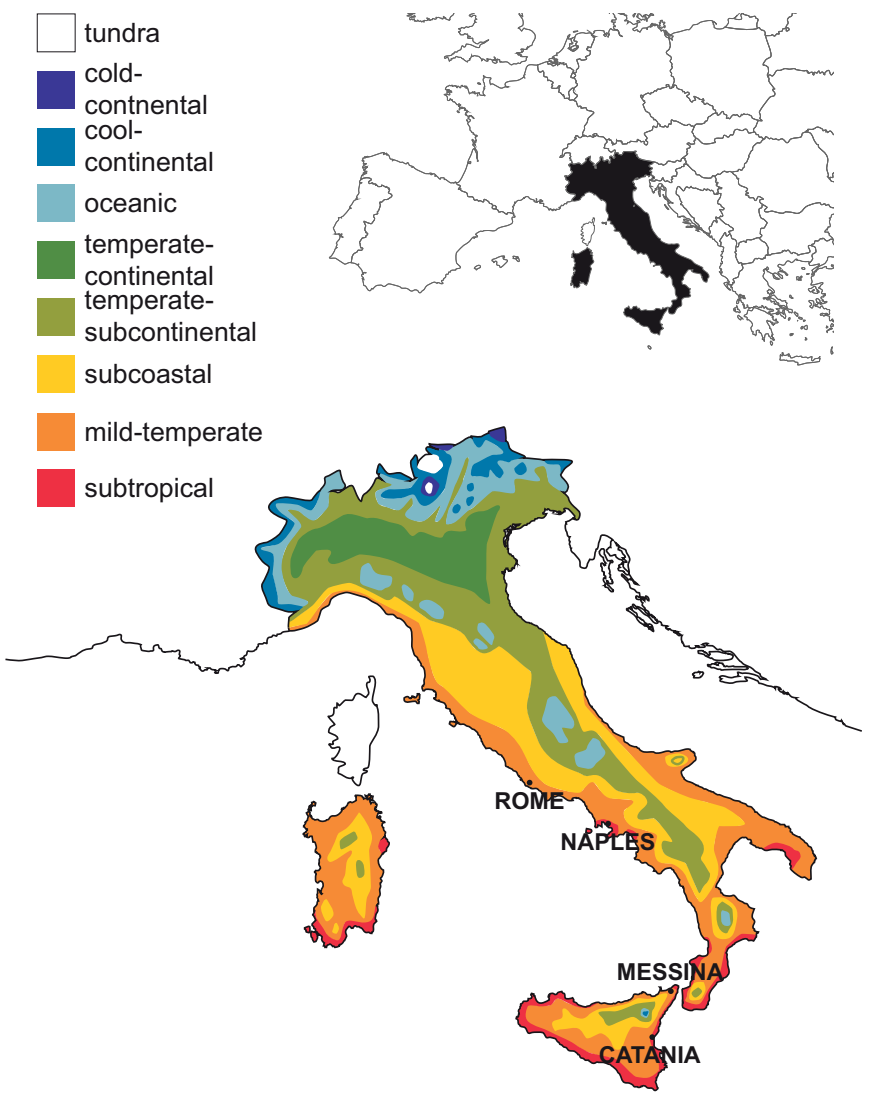

Fig. 1. Pinna climatic classification for Italian climatic zones.

- concrete structure with cladding of hollow brick or concrete/prefabricated concrete blocks or hollow masonry;

- no thermal insulation before 1976, low level $\left(0.8 \mathrm{~W} / \mathrm{m}^{2} \mathrm{~K}\right)$ between 1976 and 1991 [53].
Due to its widespread diffusion in both European and national area and its poor energy performances [50], we based the simplified simulation model on this building type. The simulation model is a south and north-facing apartment, $7 \mathrm{~m}$ width $\times 8 \mathrm{~m}$ depth, with a height of $3 \mathrm{~m}$, located in a multi-storey building. It has two opposite lowemissivity airtight glass windows of $3.45 \mathrm{~m}^{2}$, in conformity with the hygiene regulations in force in Italy. The thickness of the external concrete massive envelope can vary between two values: $30 \mathrm{~cm}$ (model A, heavy) and $18 \mathrm{~cm}$ (model B, medium-light). All the remaining surfaces are considered adiabatic.

The thermo-physical properties of the envelope for both models are set according to Table 3 : thermal transmittance $(U)$; periodic thermal transmittance $\left(Y_{\text {ie }}\right)$, which evaluates the ability of an opaque wall to phase shift and to reduce the heat flow passing through it in $24 \mathrm{~h}$, according to UNIEN ISO 13786:2008: thermal wave shift $(\varphi)$, i.e. the time (h) it takes for the heat wave to flow from outside to inside through a material; attenuation factor $\left(F_{d}\right)$, i.e. the ratio between the maximum capacitive flow and the maximum flow of the thermal wall mass; solar heat gain coefficient (SHGC), i.e. the fraction of incident solar radiation that actually enters a building through the entire window assembly as heat gain. Ground floor has an outside boundary condition of $21^{\circ} \mathrm{C}$. Internal gains (lights, people and electric equipment) are set according to a hypothetical residential occupancy pattern as in $[10,48,54]$. Occupation schedules are modelled according to a typical residential profile of use.

\subsection{Performance indicators}

During the last two decades, the time spent by people in confined environments has increased, reaching currently around $90 \%$ of a person's life. European and national 
legislation has gradually tightened quality standards on indoor spaces [55], placing indoor environmental comfort (including hygrothermal comfort and indoor air comfort IAQ) as two of the main conditions to assess the outcome of energy refurbishment.

Following an approach that considers hygrothermal indoor comfort as the goal and energy consumption as the unavoidable cost to achieve this goal, the passive performance of the building is assessed thought a comparison between the energy consumption and the hygrothermal indoor comfort achieved.

Since the current study focuses on the relationship between natural ventilation and thermal storage, it is possible to proceed according to the adaptive comfort model defined by EN 15251:2008.

The adaptive model, used to evaluate indoor hygrothermal comfort during summer, is based on the idea that outdoor climate affect indoor comfort and that humans have a natural capacity to adjust to different temperatures during different times of the year, using psychological, physiological and behavioural adaptation strategies. The model applies especially to occupant-controlled, natural conditioned spaces, where outdoor and indoor climate have a strong relationship and where occupants are keener to use conscious or unconscious adaptation strategies, being subsequently more tolerant to a wider range of comfort conditions [56]. The comfort index for the adaptive model is the operative temperature $\left(T_{o}\right)$, i.e. the uniform temperature of an imaginary black enclosure in which an occupant would exchange the same amount of heat by radiation plus convection as in the actual nonuniform environment. The SCATS survey, performed in five European Countries, has demonstrated the linear correlation between running mean of the daily mean outdoor temperatures and indoor comfort. EN 15251:2008 used the results of SCATS survey to define four categories of $T_{o}$ limits for the comfort zone in natural ventilated buildings during summer, according to the occupants' tolerance to indoor comfort conditions: high level of expectation; normal expectation; moderate expectation; values outside the criteria for the above categories. For the current study, we chose the second category, according to whom the comfort zone is equal to $T_{o}=0.33$ $T_{e}+18.8^{\circ} \mathrm{C} \pm 3{ }^{\circ} \mathrm{C}$, where $T_{e}$ is the external temperature, with $80 \%$ acceptability.

To evaluate energy performance of the building, the comfort index is associated to an ideal energy consumption value for cooling (in $\mathrm{kWh} / \mathrm{m}^{2} \mathrm{y}$ ), in order to relate the modelling to professional practice. The considered range for the ideal building plant's setting refers to the adaptive comfort temperature range, larger than Fanger's, in order to better evaluate, without overestimating the impact, the contribution of a passive strategy to the reduction of energy consumption [57].

A third synthetic indicator, air changes per hour (ach), is used to monitor that NVS guarantee the minimum air changes per hour required for IAQ $(0.7$, ach according to EN 15251:2008) inside a building with low infiltration (average 0.23 ach with Class 3 EN 12207/1999 windows). Moreover, it ensures simulation results to show the difference between systems using large cracks (e.g. facade openings) and systems with smaller cracks $\left(0.09\right.$ or $\left.0.07 \mathrm{~m}^{2}\right)$ 


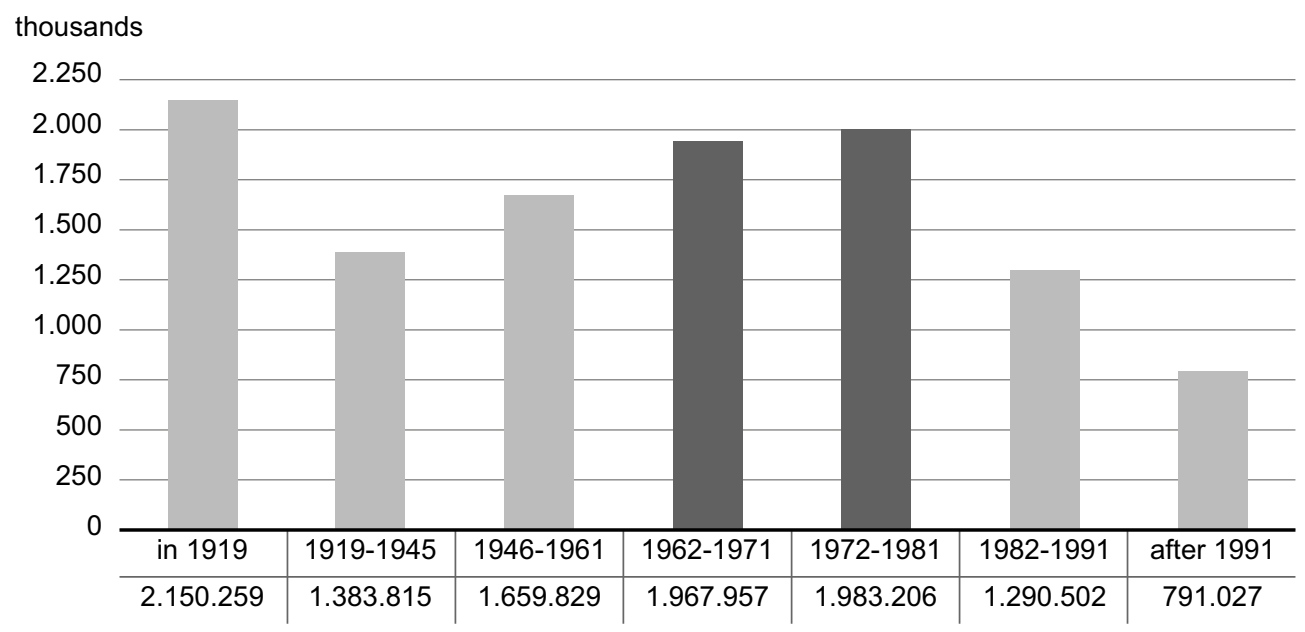

Fig. 2. Data relating to the 2001 ISTAT census of Italian building [50].

Table 3. Model envelope thermo physical properties.

\begin{tabular}{lllll}
\hline Constr. type & $U\left[\mathrm{~W} /\left(\mathrm{m}^{2} \mathrm{~K}\right)\right]$ & $Y_{\text {ie }}\left[\mathrm{W} /\left(\mathrm{m}^{2} \mathrm{~K}\right)\right]$ & $\phi[\mathrm{h}]$ & $F_{d}[-]$ \\
\hline Upper floor* & 1.34 & 0.46 & 8.37 & 0.34 \\
Lower floor* & 1.49 & 0.64 & 7.82 & 0.43 \\
30 CLS wall & 2.01 & 0.48 & 9.14 & 0.24 \\
18 CLS wall & 2.41 & 1.13 & 6.00 & 0.47 \\
Window & 1.00 & SHGC $=0.3$ & & \\
\hline
\end{tabular}

* Adiabatic.

and linear paths to avoid air flow losses. The first ones generate many air changes per hour with relatively low internal air speed, while the second ones have lower air changes per hour to prevent internal air speed becoming annoying for the occupants, with the advantage of eliminating problems of safety related to intrusion [40].

\subsection{Numerical simulation}

The software adopted for the simulations is EnergyPlus [58]. We implemented dynamic multi-zonal numerical simulation, which represents a good compromise between computation time and the level of analysis required for the current study, producing immediate results on hygrothermal conditions, air flow, comfort and energy consumption of the simulated indoor environment [59-64].

Compared to the systems described in Section 2.2, we excluded natural ventilation systems not directly affecting indoor air quality and those not immediately connected to an intervention on the single building unit. Thus we consider six NVS: single sided ventilation through facade openings (SSV), cross ventilation through facade openings (CV), inlet wind tower (IT), thermal chimney (TC), evaporative cool tower (CT), earth pipes (EP), all automatically controlled except for TC. The thermal chimney is a $18 \mathrm{~m}$ high tower with an opening with low emissivity glass on the south facade and a cross section of $0.09 \mathrm{~m}^{2}$. The evaporative cool tower is an $18 \mathrm{~m}$ high tower with a cross section of $0.09 \mathrm{~m}^{2}$ and a water pump of $0.016 \mathrm{l} / \mathrm{m}$. The earth pipe is $25 \mathrm{~m}$ long and $0.004 \mathrm{~m}$ thick concrete duct, with a cross section of $0.07 \mathrm{~m}^{2}$.
In order to simulate single sided and cross ventilation, the Airflow Network model of EnergyPlus, which calculates multi-zone airflows due to wind and surface leakage, is adopted [65]. This model allows the implementation of a ventilation control mode based on the temperature difference between indoor and outdoor temperature (if the room temperature $T_{\text {room }}>$ outdoor temperature $T_{\text {out }}$, and $T_{\text {room }}>$ summer threshold temperature $21^{\circ} \mathrm{C}$ ). Windows are opened with an opening factor set of 0.5 , with a $T_{\text {room }}$ and $T_{\text {out }}$ difference lower and upper limit set to $2^{\circ} \mathrm{C}$ and $10^{\circ} \mathrm{C}$.

We run a set of numerical multi-zonal simulations on the $\mathrm{A}$ and $\mathrm{B}$ simulation models defined, testing the performance of the different NVS and their interaction with the two thermal storage facades. The reference period is from 1st June to 30th September.

For each combination between the four locations and the two thermal storage envelope types, we defined a Benchmark Simulation Scenario (BS), set with a minimum of 0.23 ach from infiltration, and a simulation scenario for each NVS matching them to carry out a correlation analysis. The NVS simulation scenarios are indicated as follows: the first letters refer to the NVS used, the next letter is the first letter of the name of the city considered, the last one is $\mathrm{A}$ or $\mathrm{B}$, referring to the corresponding simulation model (model $\mathrm{A}$, heavy concrete envelope, model B, medium-light). The first simulation, called Discomfort Benchmark Simulation (DBS), serves as reference case for subsequent analysis and simulates A and B models for all the eight benchmark cases BS, showing the total hours of discomfort during the simulation running period. It follows the Zone Thermal 
Table 4. Discomfort hour reduction (DBS) and energy consumption reduction (EBS) in percentage, as a comparison between the performance of the benchmark simulation scenario and each natural ventilation system (NSV) simulation scenario. These are indicated as follows: the first letters refer to the NVS used, the next letter is the first letter of the strategic location considered, the last one (A: heavy concrete envelope or B: medium-light), refers to the corresponding simulation model.

\begin{tabular}{|c|c|c|c|c|}
\hline & \multicolumn{2}{|c|}{ DBS } & \multicolumn{2}{|c|}{ EBS } \\
\hline & $\mathrm{A}$ & B & $\mathrm{A}$ & B \\
\hline$S S V_{-} R$ & $93.9 \%$ & $93.2 \%$ & $88.4 \%$ & $82.1 \%$ \\
\hline$S S V_{-} N$ & $98.2 \%$ & $96.4 \%$ & $85.9 \%$ & $79.9 \%$ \\
\hline$S S V_{-}^{-} C$ & $84.7 \%$ & $78.6 \%$ & $61.7 \%$ & $55.9 \%$ \\
\hline$S S V_{-} M$ & $72.5 \%$ & $68.6 \%$ & $36.5 \%$ & $33.4 \%$ \\
\hline$C V_{-}^{-} R$ & $91.4 \%$ & $88.2 \%$ & $89.0 \%$ & $95.8 \%$ \\
\hline$C V_{-}^{-} N$ & $97.8 \%$ & $87.8 \%$ & $82.8 \%$ & $91.2 \%$ \\
\hline$C V_{-}^{-} C$ & $73.9 \%$ & $91.2 \%$ & $65.8 \%$ & $69.5 \%$ \\
\hline$C V_{-} M$ & $80.7 \%$ & $95.0 \%$ & $47.1 \%$ & $53.3 \%$ \\
\hline$T I_{-}^{-} R$ & $94.5 \%$ & $92.4 \%$ & $91.0 \%$ & $87.5 \%$ \\
\hline$T I_{-}^{-} N$ & $97.7 \%$ & $97.0 \%$ & $87.5 \%$ & $83.0 \%$ \\
\hline$T I_{-}^{-} C$ & $84.5 \%$ & $79.8 \%$ & $65.0 \%$ & $60.4 \%$ \\
\hline$T I_{-} M$ & $82.0 \%$ & $78.2 \%$ & $42.0 \%$ & $39.1 \%$ \\
\hline$T \bar{C}_{-} R$ & $58.3 \%$ & $61.5 \%$ & $40.8 \%$ & $38.0 \%$ \\
\hline$T C_{-}^{-} N$ & $55.5 \%$ & $55.0 \%$ & $38.3 \%$ & $35.2 \%$ \\
\hline$T C_{-} C^{-}$ & $26.5 \%$ & $29.1 \%$ & $7.6 \%$ & $6.4 \%$ \\
\hline$T C_{-} M$ & $26.2 \%$ & $27.4 \%$ & $15.2 \%$ & $13.9 \%$ \\
\hline$C T_{-}^{-} R$ & $98.6 \%$ & $95.7 \%$ & $33.4 \%$ & $29.5 \%$ \\
\hline$C T_{-}^{-} N$ & $74.1 \%$ & $69.9 \%$ & $9.4 \%$ & $6.5 \%$ \\
\hline$C T_{-}^{-} C$ & $85.2 \%$ & $81.9 \%$ & $20.3 \%$ & $17.3 \%$ \\
\hline$C T_{-}^{-} M$ & $73.5 \%$ & $70.2 \%$ & $21.8 \%$ & $20.3 \%$ \\
\hline$E P_{-}^{-} R$ & $100.0 \%$ & $100.0 \%$ & $96.1 \%$ & $95.1 \%$ \\
\hline$E P_{-}{ }_{-} N$ & $100.0 \%$ & $98.8 \%$ & $96.1 \%$ & $95.3 \%$ \\
\hline$E P_{-}^{-} C$ & $99.2 \%$ & $97.8 \%$ & $95.5 \%$ & $94.2 \%$ \\
\hline$E P_{-}^{-} M$ & $99.8 \%$ & $99.8 \%$ & $96.0 \%$ & $94.8 \%$ \\
\hline
\end{tabular}

Comfort CEN 15251 Adaptive Model Category II Status (Hourly), according to which a whole discomfort hour coincide with a 1 and partially discomfort hours to 0.50 or 0.25 . The hours of discomfort, in accordance with EN 15251:2008, are expressed in hours/yearly, in reference to the heat excess discomfort during summer.

For each DBS, we run five corresponding Discomfort Natural Ventilation Simulations (DNVS) to estimate the Discomfort hours Reduction Potential (DRP) for each system, expressed as a percentage of the discomfort hours reduction due to the NVS used.

The other benchmark simulation, called Energy Benchmark Simulation (EBS), calculated for all the benchmark cases (BC), has a thermostat that activates (on adaptive comfort range) a theoretical plant whenever the operative temperature of the building exceeds the normalized temperature threshold for comfort according to EN 15251, giving as a result the subsequent primary energy consumption for cooling, expressed in $\mathrm{kWh} / \mathrm{m}^{2} \mathrm{y}$.
For each EBS, we run five corresponding simulations with each natural ventilation system (ENVS), with the same thermostat and ideal plant. These simulations show the energy consumption reduction potential (ERP), i.e. the percentage of energy consumption reduction against the energy consumption of the corresponding EBS. In terms of absolute values of discomfort hours and energy consumption, the benchmark simulations confirm the results of previous research [66-68].

\section{Results}

Table 4 compares the hygrothermal comfort and the ideal energy consumption of the Benchmark Simulations (DBS and EBS) with each simulation with natural ventilation systems for the four strategic locations considered and the two thermal storages simulation models, heavy (A) and medium-light (B). 


\section{Discomfort hours reduction (\%)}

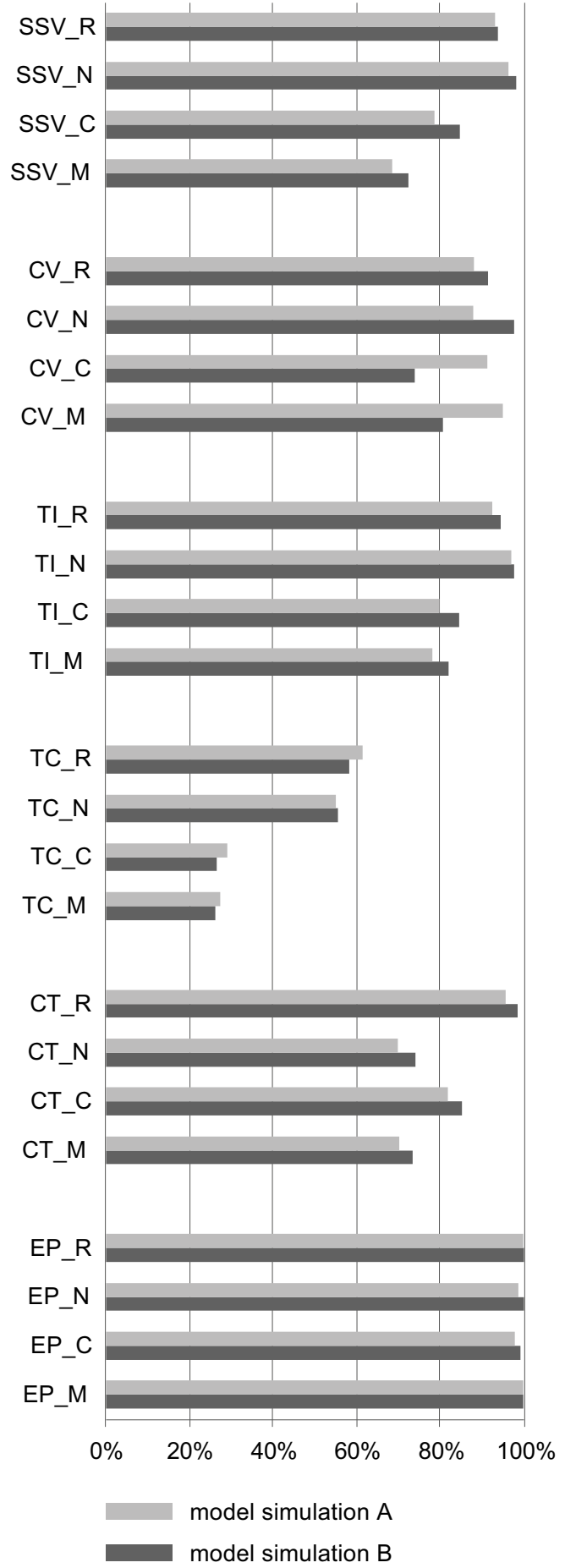

\section{Energy consumption reduction (\%)}

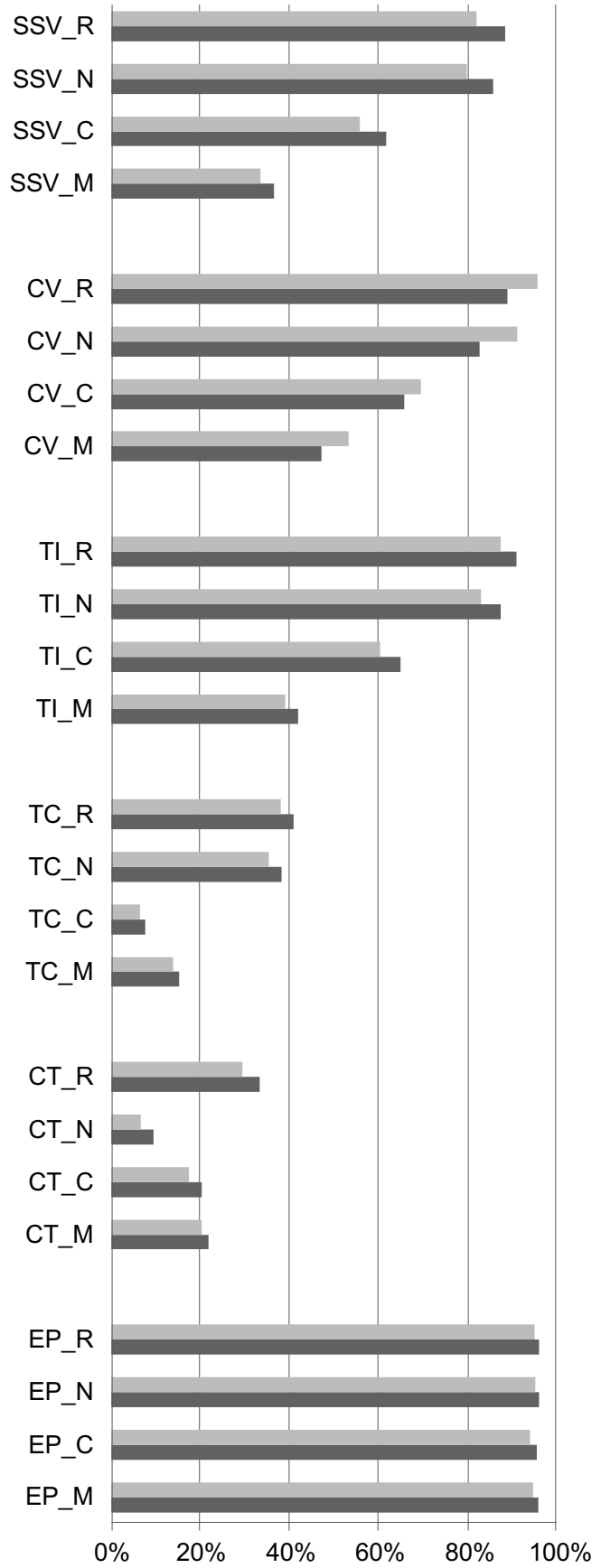

Fig. 3. Discomfort hour reduction (DBS) and energy consumption reduction (EBS) comparison between heavy (A) and medium-light (B) thermal storage system for each natural ventilation system (NSV) simulation in each strategic location.

Figure 3 compares DBS and EBS between heavy (A) and medium-light $(\mathrm{B})$ thermal storage for each natural ventilation system (NSV) simulation in each strategic location.
Single-sided ventilation (SSV) with automatic control shows a Discomfort Hours Reduction Potential (DRP) higher than $68.6 \%$ for all scenarios and a general better performance of the heavy envelope (scenario A) compared 
to the medium-light envelope (scenario $\mathrm{B}$ ), but the percentage performance difference between the two scenarios varies among the cities. Naples presents the highest DRP of $98.19 \%$ for scenario A and $96.43 \%$ for scenario B. Messina experiences the lower DRP of $72.48 \%$ for scenario A and $68.56 \%$ for scenario B. The city with the highest performance difference between the two scenarios of $6.05 \%$ is Catania, while Rome has the lowest value of $0.68 \%$.

In terms of primary energy consumption, the maximum energy consumption reduction potential (ERP) of $88.41 \%$ for scenario A and $82.10 \%$ for scenario B is in Rome, with the highest relative difference of $6.31 \%$, while Messina shows the lowest ERP of $36.48 \%$ for scenario A and $33.44 \%$ for scenario B, with the lowest percentage difference of $3.04 \%$. Considering the absolute values of energy savings between the benchmark simulations and the CV simulations, however, the primary energy saving in Catania reaches $17.45 \mathrm{kWh} / \mathrm{m}^{2} \mathrm{y}$ for scenario $\mathrm{A}$ and $16.88 \mathrm{kWh} / \mathrm{m}^{2} \mathrm{y}$ for scenario B. For the other cities, they are $14.69 \mathrm{kWh} / \mathrm{m}^{2} \mathrm{y}$ and $14.17 \mathrm{kWh} / \mathrm{m}^{2} \mathrm{y}$ in Naples, $12.90 \mathrm{kWh} / \mathrm{m}^{2} \mathrm{y}$ and $12.39 \mathrm{kWh} / \mathrm{m}^{2} \mathrm{y}$ in Rome and $10.88 \mathrm{kWh} / \mathrm{m}^{2} \mathrm{y}$ and $10.77 \mathrm{kWh} / \mathrm{m}^{2} \mathrm{y}$ in Messina, for scenario and $\mathrm{B}$ respectively.

Cross ventilation (CV) with automatic control has a maximum DRP of $97.76 \%$ in Naples for scenario A and of $94.97 \%$ in Messina for scenario B. The maximum performance difference between the two scenarios is in Messina, where scenario B exceeds scenario A of $17.31 \%$. Rome displays the minimum relative difference of $3.24 \%$ between scenario A and scenario B respectively.

ERP for CV is always higher for scenario B compared to scenario A, for all the cities considered. Rome shows the maximum ERP of $95.80 \%$ and $89.02 \%$ for scenario B and scenario A respectively, while the minimum ERP of $53.32 \%$ and $47.12 \%$ for scenario B and scenario A respectively is in Messina. Naples has the highest relative difference of $8.43 \%$ between scenario $\mathrm{B}$ and $\mathrm{A}$, while Catania has the lowest, $3.72 \%$. The maximum absolute values of primary energy saving are $22.09 \mathrm{kWh} / \mathrm{m}^{2}$ y for scenario B and $19.74 \mathrm{kWh} / \mathrm{m}^{2}$ y for scenario A in Catania; they are $17.15 \mathrm{kWh} / \mathrm{m}^{2} \mathrm{y}$ and $15.08 \mathrm{kWh} / \mathrm{m}^{2} \mathrm{y}$ in Naples, $17.87 \mathrm{kWh} / \mathrm{m}^{2} \mathrm{y}$ and $14.74 \mathrm{kWh} / \mathrm{m}^{2} \mathrm{y}$ in Messina and $15.61 \mathrm{kWh} / \mathrm{m}^{2} \mathrm{y}$ and $14.10 \mathrm{kWh} / \mathrm{m}^{2} \mathrm{y}$ in Rome, for scenario B and A respectively.

Inlet wind tower (IT) with automatic control achieves a DRP higher than $78.18 \%$ for all scenarios, with a general better performance of scenario A compared with scenario B. Naples presents the maximum DRP of $97.70 \%$ for scenario A and $97.01 \%$ for scenario B, while Messina depicts the minimum DRP of $81.95 \%$ and $78.18 \%$ for scenario $\mathrm{A}$ and $\mathrm{B}$ respectively. The maximum performance difference of $4.69 \%$ between scenario A and B is in Catania and the minimum of $0.70 \%$ in Naples.

Rome shows the maximum ERP of $90.97 \%$ for scenario $\mathrm{A}$ and $87.45 \%$ for scenario B; Messina has the lowest values of ERP of $42.01 \%$ for scenario $\mathrm{A}$ and $30.09 \%$ for scenario B. in terms of percentage difference between the two scenarios, Catania exhibits the highest value of $4.59 \%$ and Messina the lowest value of $2.92 \%$. The absolute values of primary energy savings for scenario $\mathrm{A}$ and $\mathrm{B}$ are $16.02 \mathrm{kWh} / \mathrm{m}^{2} \mathrm{y}$ and $15.57 \mathrm{kWh} / \mathrm{m}^{2} \mathrm{y}$ in Catania, $11.17 \mathrm{kWh} / \mathrm{m}^{2} \mathrm{y}$ and $10.76 \mathrm{kWh} / \mathrm{m}^{2} \mathrm{y}$ in Naples, $10.88 \mathrm{kWh} / \mathrm{m}^{2} \mathrm{y}$ and $10.63 \mathrm{kWh} / \mathrm{m}^{2} \mathrm{y}$ in Rome, $10.33 \mathrm{kWh} / \mathrm{m}^{2} \mathrm{y}$ and $10.11 \mathrm{kWh} / \mathrm{m}^{2} \mathrm{y}$ in Messina.

Thermal chimney (TC) without automatic control has a maximum DRP of $61.50 \%$ for scenario B and $58.28 \%$ for scenario A, a maximum percentage difference of $3.22 \%$ between scenario $\mathrm{B}$ and $\mathrm{A}$ in Rome and a minimum DRP of $26.20 \%$ for scenario A and $27.37 \%$ for scenario B in Catania. The minimum percentage difference between scenario A and B is in Naples, with a value of $0.43 \%$.

ERP of $40.84 \%$ for scenario A and $37.98 \%$ for scenario B in Rome is the maximum value, while Catania has the minimum values of $7.62 \%$ and $6.36 \%$. Catania has also the minimum percentage difference between the two scenarios of $1.25 \%$, while Naples has the maximum percentage difference of $3.03 \%$. The absolute values of energy saving are $4.58 \mathrm{kWh} / \mathrm{m}^{2} \mathrm{y}$ and 4.25 in Naples, $4.56 \mathrm{kWh} / \mathrm{m}^{2} \mathrm{y}$ and $4.27 \mathrm{kWh} / \mathrm{m}^{2} \mathrm{y}$ in Rome, $3.57 \mathrm{kWh} / \mathrm{m}^{2} \mathrm{y}$ and $3.41 \mathrm{kWh} /$ $\mathrm{m}^{2} \mathrm{y}$ in Messina, $1.36 \mathrm{kWh} / \mathrm{m}^{2} \mathrm{y}$ and $1.17 \mathrm{kWh} / \mathrm{m}^{2} \mathrm{y}$ in Catania, for scenario $\mathrm{A}$ and $\mathrm{B}$ respectively.

Evaporative cool tower (CT) with automatic control presents in Rome the highest DRP of $98.56 \%$ and $95.69 \%$ for scenario A and B respectively; the lowest DRP value of $73.48 \%$ for scenario A is in Messina and the lowest DRP of $69.89 \%$ for scenario B is in Naples. Naples depicts the maximum percentage difference of $4.18 \%$ between the two scenarios and Rome the minimum of $2.87 \%$.

Rome has the maximum ERP of $33.38 \%$ for scenario A and $29.48 \%$ for scenario B, while Naples has the minimum values of $9.42 \%$ and $6.54 \%$. The maximum percentage difference of ERP of $3.89 \%$ and the minimum of $1.51 \%$ occur in Rome and Messina respectively. In terms of absolute values, the energy saving are $5.26 \mathrm{kWh} / \mathrm{m}^{2} \mathrm{y}$ and $5.15 \mathrm{kWh} / \mathrm{m}^{2} \mathrm{y}$ in Messina, $3.80 \mathrm{kWh} / \mathrm{m}^{2} \mathrm{y}$ and $3.41 \mathrm{kWh} /$ $\mathrm{m}^{2} \mathrm{y}$ in Rome, $3.68 \mathrm{kWh} / \mathrm{m}^{2} \mathrm{y}$ and $3.25 \mathrm{kWh} / \mathrm{m}^{2} \mathrm{y}$ in Catania, $1.15 \mathrm{kWh} / \mathrm{m}^{2} \mathrm{y}$ and $0.81 \mathrm{kWh} / \mathrm{m}^{2} \mathrm{y}$ in Naples for scenario $\mathrm{A}$ and $\mathrm{B}$ respectively.

Earth pipes (EP) with automatic control displays a maximum DRP of $100 \%$ in Roma and Naples for scenario A and of $99.96 \%$ in Rome for scenario B. Catania presents the maximum percentage difference of $1.38 \%$ and Messina the minimum of $0.01 \%$.

ERP exhibits maximum values of $96.10 \%$ and $95.26 \%$ in Naples and minimum values of $95.55 \%$ and $94.15 \%$ in Catania for scenario A and B respectively. Catania has the maximum percentage difference of $1.39 \%$ and Naples the minimum of $0.84 \%$. The absolute values of energy savings are $24.00 \mathrm{kWh} / \mathrm{m}^{2} \mathrm{y}$ and $23.13 \mathrm{kWh} / \mathrm{m}^{2} \mathrm{y}$ in Messina, $17.65 \mathrm{kWh} / \mathrm{m}^{2} \mathrm{y}$ and $17.34 \mathrm{kWh} / \mathrm{m}^{2} \mathrm{y}$ in Catania, $11.81 \mathrm{kWh} / \mathrm{m}^{2} \mathrm{y}$ and $11.74 \mathrm{kWh} / \mathrm{m}^{2} \mathrm{y}$ in Naples, $11.00 \mathrm{kWh} / \mathrm{m}^{2} \mathrm{y}$ and $10.94 \mathrm{kWh} / \mathrm{m}^{2} \mathrm{y}$ in Rome for scenario $\mathrm{B}$ and $\mathrm{A}$ respectively.

\section{Discussion}

Figures 4 and 5 represents the relation between the four cities considered for the study, NVS, simulation scenarios and the corresponding ERP and DRP respectively, 


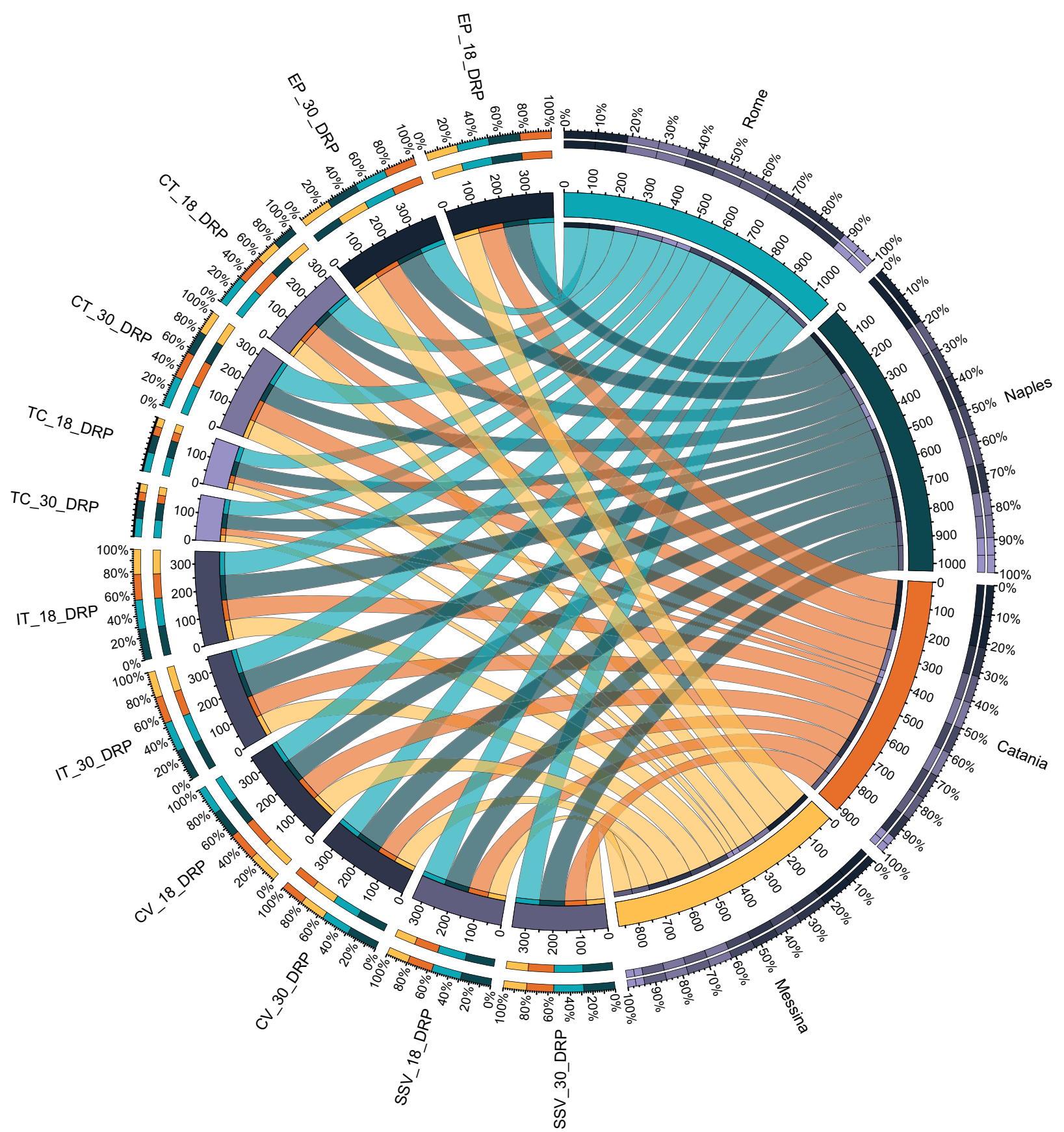

Fig. 4. Relation between the four cities considered for the study, NVS, simulation scenarios and the corresponding DRP.

according to a circular layout data visualisation (Circos [69]), ideal to explore connections between objects. In those diagrams, all the relevant variables taken into account in the research are on the perimeter of a circle. ERP (Fig. 2) and DRP (Fig. 3) for each combination of NVS and simulation scenarios are on the left side, every one coinciding with a circular sector in a shade of blue: the bigger the sector and the darker the colour, the higher the combination efficacy. On the right side, the data are outlined in accordance to the considered cities. The circular sector are cyan for Rome, green for Naples, orange for Catania and yellow for Messina: the bigger the circular sector, the higher the ERP and DRP (for Figs. 2 and 3 respectively) of the NVS for that city. The thickness of the strands linking cities to NVS for each simulation scenario are proportional to ERP (in Fig. 2) and DRP (in Fig. 3) values; therefore, the thicker the strand, the higher the combination efficacy within the city.

Thermal range emerges in the study as a significant factor for a number of NVS: cities with a higher thermal range, such as Naples and Catania, exhibits a higher DRP (for SSV, TC) and ERP (for SSV, CV, IT) than the ones with a lower thermal range, namely Messina. The finding is in accordance to Santamouris [15] on night ventilation. For SSV system, Naples and Catania have a mean of DRP and ERP of approximately $90 \%$ and $75 \%$ respectively, while Messina has 


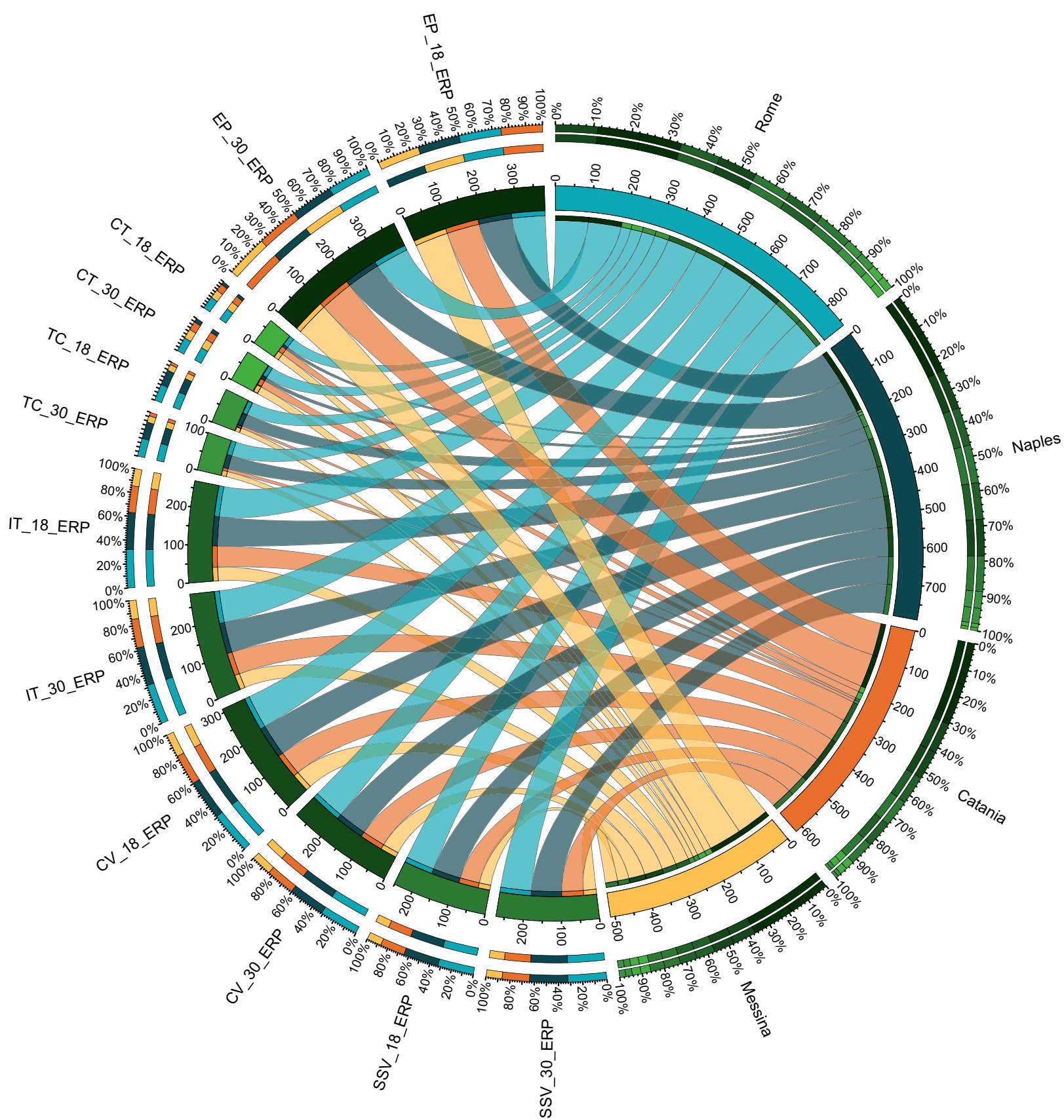

Fig. 5. Relation between the four cities considered for the study, NVS, simulation scenarios and the corresponding ERP.

a mean of DRP and ERP of approximately $70 \%$ and $35 \%$. For $\mathrm{CV}$, the notable increase in air flow rates compared to SSV (1.5 times more), results in a reduced effect of thermal range, levelling the difference between DRP. On the contrary, thermal range determines an increase of ERP, which is approximately $82 \%$ for Rome, Naples and Catania and $50 \%$ for Messina. IT shows a similar influence of thermal range on ERP, approximately $80 \%$ for Rome, Naples and Catania and $40 \%$ for Messina. TC has a higher DRP of around $55 \%$ compared with the $26 \%$ of Messina. However, the absence of automatic control reduces the overall efficacy of the system for climates with higher mean air temperature, resulting in the lower DRP of Catania.
The highest mean outdoor air temperatures, corresponding to the highest outdoor hygrothermal discomfort, induce a slight reduction of NVS efficiency. For SSV, DRP for Rome and Naples is approximately $95 \%$, while it is $82 \%$ for Catania; ERP is approximately $84 \%$ for Rome and Naples and $59 \%$ for Catania. For CV, Rome and Naples have a DRP of approximately $91 \%$ and a ERP of approximately $90 \%$, while the DRP and ERP of Catania are approximately $83 \%$ and $68 \%$ respectively. For IT, the DRP and ERP of both Rome and Naples are approximately $94 \%$ and $87 \%$ compared to the $82 \%$ and $63 \%$ of Catania. The DRP and ERP of TC are approximately $58 \%$ and $38 \%$ for Rome and Naples and approximately $27 \%$ and $7 \%$ for Catania. 
The effect of thermal storage on NVS is not so clearly recognizable as in previous studies [10,48]. In fact, according to [10], apartments located in multi-storey buildings, exemplified by the north-south double exposed simulation model, are less sensible to outdoor climatic variations on account of the reduced influence of solar radiation on the envelope, which results in a reduced effect of thermal storage on indoor microclimate. For SSV, higher thermal storage corresponds in every city to higher ERP; thermal storage appears to be more effective for higher thermal ranges, as the EPR of scenario B for Naples, Rome un Messina is approximately $6 \%$ exceeds scenario $\mathrm{B}$, as opposed to the $3 \%$ of Messina.

\section{Conclusion}

The present study analyses the contribution of natural ventilation systems, coupled with thermal storage building elements, to summer indoor comfort for different cities in Italy with different climatic condition and thermal ranges. It highlights the complexity of implementing natural ventilation systems within the building design project, stressing the significance of dynamic simulation to take into account all the interrelated factors involved.

Thermal range proves a critical aspect for summer comfort in warm climates, especially for natural ventilation systems, requiring to be broadly included among climatic reference data enhancing energy efficient building design.

The research remarks the overall efficiency of every natural ventilation system, even the non-invasive ones such as single-sided ventilation and cross ventilation, that are therefore suitable to be implemented in energy refurbishment, especially for historical and listed buildings, as they often require merely automatic control to operate.

The current research investigates a confined topic concerning natural ventilation system performance analysis trough dynamic simulation for four Italian cities. Other possible future research themes include:

- an overall view of several passive systems performance and their combination;

- the extension of simulation model characteristics, taking into account different orientation and building technical, functional and spatial systems and layouts, such as facade types or the internal apartments subdivision, and considering apartments in "critical" positions, such as rooftop or ground floor or angle position;

- the broadening of climatic and microclimatic factor considered and their influence on ventilation [54];

- the annual simulation of natural ventilation systems, to verify their performance under climatic conditions where summer and winter comfort are both significant;

- the evaluation and monitoring of case studies, to verify the systems performances in an actual contest and to assess the simulation capacity of giving a reliable representation of real conditions.
The overall goal of performance simulation of buildings is ultimately the broadening of architectural practice methods, to capitalize on contributions from various professionals, including information on technical physics, building climatology, information technology.

\section{Nomenclature}

HVAC heating, ventilation and air conditioning

IAQ indoor air quality

NV natural ventilation

NVS natural ventilation system

CV cross ventilation

SSV single-sided ventilation

DV downward ventilation

UV upward ventilation

VT ventilation techniques

BV body ventilation

SV structural ventilation

RV room ventilation

HET heat exchange type

PE physical elements

NPE non-physical elements

TR thermal range

$U$ thermal transmittance

$Y_{\text {ie }} \quad$ periodic thermal transmittance

$\phi \quad$ thermal wave shift

$F_{d} \quad$ attenuation factor

SHGC solar heat gain coefficient

$T_{o} \quad$ operative temperature

$T_{e} \quad$ external temperature

IT inlet wind tower

TC thermal chimney

CT evaporative cool tower

EP earth pipes

BS benchmark simulation scenario

DBS discomfort benchmark simulation

DNVS discomfort natural ventilation simulations

DRP discomfort hours reduction potential

EBS energy benchmark simulation

BC benchmark cases

ERP energy consumption reduction potential

\section{References}

1. F. Ardente, M. Beccali, M. Cellura, M. Mistretta, Energy and environmental benefits in public buildings as a result of retrofit actions, Renew. Sustain. Energy Rev. 15, 460 (2011)

2. M. Economidou, B. Atanasiu, C. Despret, J. Maio, I. Nolte, O. Rapf, Europe's Buildings under the Microscope, in $A$ Country-by-Country Review of the Energy Performance of Buildings, Build. Perform. Inst. Eur. BPIE (2011)

3. C.-H. Baek, S.-H. Park, Changes in renovation policies in the era of sustainability, Energy Build. 47, 485 (2012)

4. Z. Ma, P. Cooper, D. Daly, L. Ledo, Existing building retrofits: methodology and state-of-the-art, Energy Build. 55, $889(2012)$ 
5. EP, Directive 2010/31/EU of the European Parliament and of the Council of 19 May 2010 on the energy performance of buildings (2010)

6. European Council, Appendix: European Council Action Plan (2007-2009), in Bruss. Eur. Counc. 89 March 2007 Pres. Conclus, Bruxelles (2007)

7. R. Roda, C. Monti, BolognaFiere, Salone internazionale dell'industrializzazione edilizia, in Costruire sostenibile: il Mediterraneo: 2001, Alinea, Firenze (2001)

8. R. Banham, The architecture of the well-tempered environment (Architectural P, London, 1969)

9. E. De Oliveira, S. Yannas, Energy and buildings for temperate climates: a Mediterranean regional approach, in Proc. Sixth Int. Plea Conf. Porto Portu. (1989)

10. F. Calcerano, C. Cecchini, Passive cooling strategies in refurbishment of Mediterranean buildings: simulation analysis of thermal mass and natural ventilation combination, in Proc. 2nd IBPSA Italy Conf., 4-6 February, BSA 2015, Bozen, Bolzano, Italy (2015)

11. EC, Directive 2002/91/EC of the European Parliament and of the Council of 16 December 2002 on the energy performance of buildings, 2002

12. A. Prada, P. Baggio, M. Baratieri, P. Romagnoni, A. Gasparella, E. Bettanini, Consumi energetici e certificazione energetica: situazione estiva ed invernale in Italia e in Europa, in Energ. Lo Sviluppo Sostenibile, Dario Flaccovio Editore, Palermo (2008), pp. 1-6

13. M. D'Orazio, C. Di Perna, E. Di Giuseppe, The effects of roof covering on the thermal performance of highly insulated roofs in Mediterranean climates, Energy Build. 42, 1619 (2010)

14. L. Tronchin, K. Fabbri, Energy performance building evaluation in Mediterranean countries: comparison between software simulations and operating rating simulation, Energy Build. 40, 1176 (2008)

15. M. Santamouris, D. Asimakopoulos, Passive cooling of buildings (James \& James Ltd, London, 1996)

16. O.-H. Kwon, M.-H. Kim, A.-S. Choi, J.-W. Jeong, Energy saving potential of a hybrid ventilation system integrated with heat storage material, Energy Build. 57, 346 (2013)

17. P. Heiselberg, Principles of hybrid ventilation (Aalborg University, Aalborg, Denmark, 2002)

18. IEA, IEA ECES Energy Conservation through Energy Storage (2012)

19. B. Moujalled, R. Cantin, G. Guarracino, Comparison of thermal comfort algorithms in naturally ventilated office buildings, Energy Build. 40, 2215 (2008)

20. R.J. de Dear, G.S. Brager, Thermal comfort in naturally ventilated buildings: revisions to ASHRAE Standard 55, Energy Build. 34, 549 (2002)

21. J.F. Nicol, M.A. Humphreys, B.W. Olesen, A stochastic approach to thermal comfort - occupant behavior and energy use in buildings, in Tech. Symp. Pap. - 2004 Annu. Meet. Am. Soc. Heat. Refrig. Air-Cond. Eng. Nashv., TX, USA, 26-30 June 2004, Code 6500 (2004)

22. O. Seppänen, W.J. Fisk, Association of ventilation system type with SBS symptoms in office workers, Indoor Air 12,98 (2002)

23. J.E. Braun, Load control using building thermal mass, J. Sol. Energy Eng. 125, 292 (2003)
24. L. Stephan, A. Bastide, E. Wurtz, B. Souyri, Ensuring desired natural ventilation rate by means of optimized openings, in Proc. 11th Int. IBPSA Conf. - Build. Simul. 2009 BS 2009 Glasg., UK, July 2007 (2007)

25. G. Augenbroe, Trends in building simulation, Build. Environ. 37, 891 (2002)

26. J.L.M. Hensen, Towards more effective use of building performance simulation in design, in Proc. 7th Int. Conf. Des. Decis. Support Syst. Archit. Urban Plan., 2-5 July Eindh, edited by J.P. Leeuwen, H.J.P. Van Timmermans (Eindh. Univ. Technol., 2004)

27. N. Lechner, Heating, cooling, lighting: sustainable design methods for architects (John Wiley \& Sons, Hoboken, NJ, 1991)

28. T. Herzog, Deutsches Architekturmuseum, Thomas Herzog: Architektur + Technologie $=$ architecture + technology (Prestel, Munchen, New York, 2002)

29. S. Attia, M. Hamdy, W. O'Brien, S. Carlucci, Assessing gaps and needs for integrating building performance optimization tools in net zero energy buildings design, Energy Build. 60, $110(2013)$

30. ECES (Energy Conservation Through Energy Storage Programme), Annual Report, IEA (International Energy Agency), 2012

31. J. Karlsson, Possibilities of using thermal mass in buildings to save energy, cut power consumption peaks and increase the thermal comfort (Div. of Building Materials LTH, Lund University, 2012), http://lup.lub.lu.se/record/2518432 (accessed on: 2014/18/02)

32. Y. Li, P. Xu, Thermal mass design in buildings - heavy or light? Int. J. Vent. 5, 143 (2006)

33. C.A. Balaras, The role of thermal mass on the cooling load of buildings. An overview of computational methods, Energy Build. 24, 1 (1996)

34. International PLEA Conference, International PLEA Organisation, Energy and buildings for temperate climates: a Mediterranean regional approach, in Proceedings of the Sixth International PLEA Conference, Porto, Portugal, 27-31 July 1988 (Published on behalf of the International PLEA Organisation by Pergamon Press, Oxford, New York, 1989), 1st ed.

35. S. Szokolay, Passive and low energy design for thermal and visual comfort, in Passive Low Energy Ecotechniques, Proc. Third Int. PLEA Conf. Mex. City Mex., 6-11 August 1984 (1985), pp. 11-28

36. C. Diakaki, E. Grigoroudis, N. Kabelis, D. Kolokotsa, K. Kalaitzakis, G. Stavrakakis, A multi-objective decision model for the improvement of energy efficiency in buildings, Energy 35, 5483 (2010)

37. C.A. Balaras, K. Droutsa, E. Dascalaki, S. Kontoyiannidis, Heating energy consumption and resulting environmental impact of European apartment buildings, Energy Build. 37, $429(2005)$

38. M. Grosso, Il raffrescamento passivo degli edifici: concetti, precedenti architettonici, criteri progettuali, metodi di calcolo e casi di studio (Maggioli, Rimini, 1997)

39. F. Tucci, Atlante dei sistemi tecnologici per l'architettura bioclimatica: ventilazione naturale negli edifici/Atlas of Technological Systems for Bioclimatic Architecture (Natural ventilation, Alinea Editrice, Firenze, 2012) 
40. F. Allard, Natural ventilation in buildings: a design handbook (James \& James Ltd, London, 1998)

41. T. Chenvidyakarn, Buoyancy effects on natural ventilation (Cambridge University Press, Cambridge, 2013)

42. P.F. Linden, The fluid mechanics of Natural Ventilation, Annu. Rev. Fluid Mech. 31, 201 (1999)

43. C.C. Siew, A.I. Che-Ani, N.M. Tawil, N.A.G. Abdullah, M. Mohd-Tahir, Classification of natural ventilation strategies in optimizing energy consumption in Malaysian office buildings, Procedia Eng. 20, 363 (2011)

44. C.M. Mak, J.L. Niu, C.T. Lee, K.F. Chan, A numerical simulation of wing walls using computational fluid dynamics, Energy Build. 39, 995 (2007)

45. A. Aldawoud, R. Clark, Comparative analysis of energy performance between courtyard and atrium in buildings, Energy Build. 40, 209 (2008)

46. N. Baker, M. Standeven, PASCOOL - Comfort Group Final Report, 1995

47. A. Mahdavi, C. Pröglhöf, A model-based method for the integration of natural ventilation in indoor climate systems operation, in Proc. 9th Int. IBPSA Conf., BS 2005 Montr. Can., 15-18 August 2005 (2005)

48. F. Calcerano, C. Cecchini, Mediterrean building refurbishment: thermal mass and natural ventilation simulated control, in Proc. 5th Ger. - Austrian IBPSA Conf. BA USIM2014 Hum. Centered Build., 22-24 Sept. 2014, Aachen, Ger. (2014), p. 8

49. B. Givoni, Effectiveness of mass and night ventilation in lowering the indoor daytime temperatures. Part I: 1993 experimental periods, Energy Build. 28, 25 (1998)

50. V. Corrado, I. Ballarini, S.P. Corgnati, N. Talà, Building Typology Brochure - Italy (Fascicolo sulla Tipologia Edilizia Italiana, 2012)

51. L.D. Decanini, L. Liberatore, F. Mollaioli, Damage suffered by RC buildings during the 2009 L'Aquila earthquake, a general overview and a case study, in Proc. 14th Eur. Conf. Earthq. Eng. (2010)

52. L. Sorrentino, E. Raglione, D. Liberatore, L.D. Decanini, Chiesa di San Biagio D'Amiternum a L'Aquila (Catalogo sismico locale e meccanismi di collasso, Textus, L'Aquila, 2011)

53. M. Pasca, Il costruito italiano: tipologie, problematiche, interventi pre e post sisma, Tafter J. Esperienze E Strum. Cult. E Territ. (2012)

54. F. Calcerano, L. Martinelli, Numerical optimisation through dynamic simulation of the position of trees around a standalone building to reduce cooling energy consumption, Energy Build. 112, 234 (2016)

55. G. Lopardo, Un modello matematico di termoregolazione del corpo umano (Università degli studi di Salerno - Dipartimento di Ingegneria Meccanica, 2011), http://elea.unisa. it:8080/handle/10556/219 (accessed on: 2014/16/05)
56. R. de Dear, G.S. Brager, Developing an adaptive model of thermal comfort and preference, Cent. Built Environ. (1998), http://escholarship.org/uc/item/4qq2p9c6 (accessed on: 2016/30/05)

57. S.P. Corgnati, E. Fabrizio, M. Filippi, The impact of indoor thermal conditions, system controls and building types on the building energy demand, Energy Build. 40, 627 (2008)

58. R.H. Henninger, M.J. Witte, EnergyPlus Testing with ASHRAE 1052-RP Toolkit - Building Fabric Analytical Tests (Lawrence Berkeley Natl. Lab., USA, 2011)

59. C. Morbitzer, Towards the integration of simulation in the Building Design Process, PHD thesis, Energy System Research Unit, University of Strathcylde, 2003

60. J.A. Clarke, Energy simulation in building design (Butterworth-Heinemann, Oxford, 2001)

61. Q. Chen, Ventilation performance prediction for buildings: a method overview and recent applications, Build. Environ. 44, 848 (2009)

62. J. Hensen, Integrated building airflow simulation, in Adv. Build. Simul. (Spon Press, New York and London, 2003)

63. A. Foucquier, F. Suard, S. Robert, L. Stephan, A. Jay, State of the art in building modelling and energy performances prediction: a review, Renew. Sustain. Energy Rev Renew. Sustain. Energy Rev. 23, 272 (2013)

64. R. Ramponi, B. Blocken, CFD simulation of cross-ventilation for a generic isolated building: impact of computational parameters, Build. Environ. 53, 34 (2012)

65. NREL, Energyplus Input Output Reference (2013), http:// apps1.eere.energy.gov/buildings/energyplus/pdfs/inputout putreference.pdf

66. P. Cesaratto, M. De Carli, Studio comparativo tra fabbisogni energetici netti, lato edificio, sia per la climatizzazione estiva che per quella invernale di edifici residenziali e del settore terziario situati in climi differenti (ENEA, Roma, 2010), http://www.enea.it/it/Ricerca_svi luppo/documenti/ricerca-di-sistema-elettrico/fabbisogniconsumi-energetici/4-univ-pd-ob-b-1.pdf (accessed on: 2014/16/05)

67. S. Sibilio, M. D'Agostino, M. Fatigati, M. Citterio, Valutazione dei consumi nell'edilizia esistente e benchmark mediante codici semplificati: analizi di edifici residenziali (ENEA, Roma, 2009)

68. P. Caputo, G. Costa, V. Zanotto, Rapporto sulla validazione del modulo edificio - sistema elettrico (2011)

69. M. Krzywinski, J.E. Schein, I. Birol, J. Connors, R. Gascoyne, D. Horsman, S.J. Jones, M.A. Marra, Circos: an information aesthetic for comparative genomics (Genome Res Publ. Adv., 2009)

Cite this article as: F. Calcerano, C. Cecchini and L. Martinelli: Numerical analysis of passive strategies for energy retrofit of existing buildings in Mediterranean climate: thermal mass and natural ventilation combination. Sust. Build. 2, 4 (2017). 